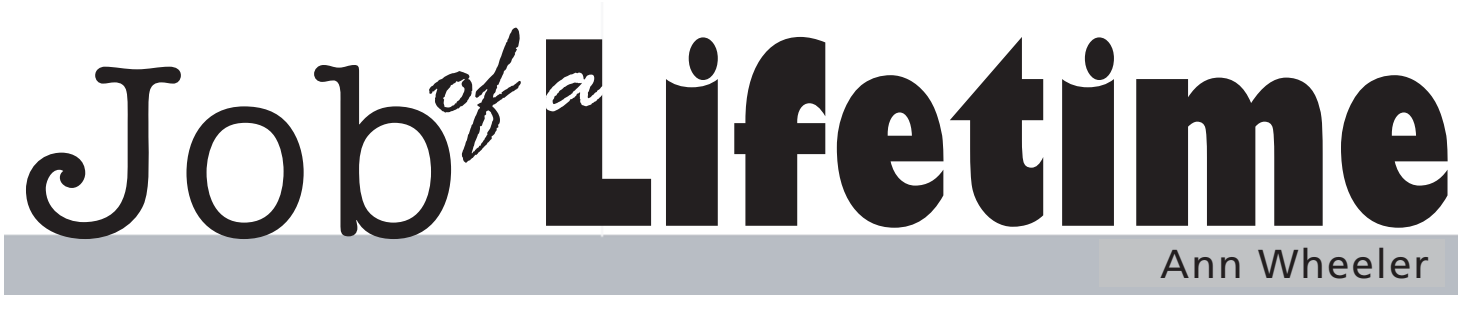

\title{
Teaching old dirt new tricks
}

M arianne Stowell Bracke is the agricultural sciences information specialist at Purdue University. She recently shared with me why she loves her job. After our chat, I have a deepened appreciation for agricultural sciences and a better understanding of one librarian's important role in supporting this field.

\section{What is Agricultural Science?}

At Purdue, agricultural sciences includes the departments of agronomy, animal sciences, botany and plant pathology, entomology, food science, forestry and natural resources, agricultural education, and horticulture and landscape architecture.

The range of subjects suits Bracke. "I like the variety. Each department is a little bit different in how they work with the library. I work with undergrads, grads, researchers, and the Agricultural Extension. I provide reference, instruction, collection

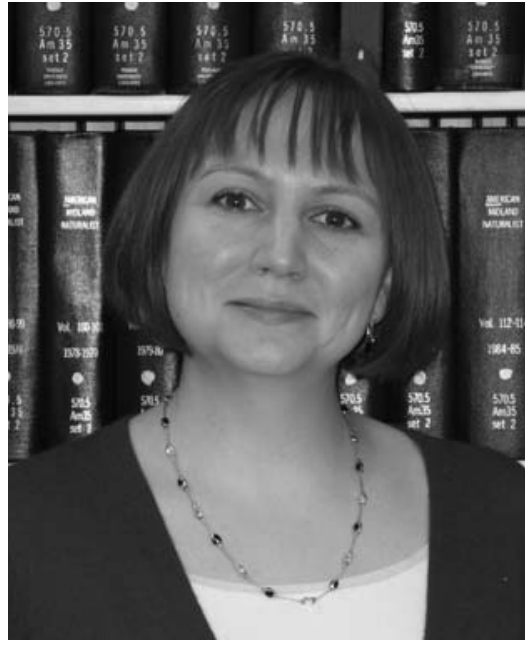

Marianne Stowell Bracke her job. She enjoys this aspect of her work and values the opportunity to collaborate with her peers. "I really like the project part of my job. It brings so much of it together. I get to work with faculty, I get to work with my colleagues, we get to create something new."

In one such collaboration, Bracke and Purdue's GIS librarian are working with the agronomy department to digitize soil surveys of the local county. "Soil surveys have always been of interest to me. The older soil surveys aren't being digitized in any systematic way, although the information is still valuable. It can show how the soil and land use have changed over the last hundred years, how society has moved from small farms to agrobusiness and more land development, greater population, that sort of thing."

"Our agronomy department is celebrating its centennial, and we wanted to do development; I do a little bit of everything in that regard."

Bracke raves about the faculty she works with. "I really love the people that are drawn to the field of agriculture. The scientists and professors I work with are very down-to-earth people. They're often very creative, very inventive, but also very practical. It's easy to build working relationships with them."

\section{Digitizing dirt}

Bracke is a tenure-track faculty member, so research and publishing are a required part of something to help mark that. We didn't want to just do a straight digitization project, so in addition to digitizing the soil survey text and capturing the map as a PDF, we turned the map into a GIS layer that is compatible with GIS files of the same area today. It makes the map more of a living document rather than simply a recreation of a picture."

The response from faculty has been exciting. "People had no idea that the library

Ann Wheeler is the librarian at the Maryland Department of Natural Resources. Have a story idea for Job of a Lifetime? E-mail Ann at awheeler@dnr.state.md.us 
could do a project like that. It reminds them that there's probably data between different departments that people might like to share, but because they're in different departments, they don't necessarily talk to each other. As librarians, we have different boundaries and can talk between departments. It's been a great promotional tool for the library, and already it's generated some other project ideas."

Bracke sees this project growing and developing in the future. "Ultimately what we're doing is creating a framework with the GIS layer. We can hang any kind of information off that framework. There's no reason we'd have to limit ourselves to agromony data."

\section{Embedded librarianship}

In another collaboration, Bracke is working with Purdue's business librarians to provide embedded librarian services to an agricultural marketing class, where students are creating and implementing marketing plans for various pork products sold at Purdue's campus meat shop. Bracke

\section{Agricultural Sciences Information Specialist}

What: Agricultural Sciences

Where: Purdue University

For more information, visit:

www.lib.purdue.edu they had the staffing and time to support it, and they did. It was really satisfying because the two faculty members teaching the class immediately saw the benefit of it. We didn't have to sell them on it."

It's been an enriching experience for both Bracke and the students. "This is a challenging class. It's only the second week of classes, and the students are still getting their head around what questions to ask. It's really rewarding to be in on learning at that level. It helps me understanding how students think, for example, why do they think Google has everything? Or why do they get attached to one library database and use it for everything?"

She's also learned a lot about pork products over the course of the class. "Did you know there's actually 15 grades of bacon? There's the kind that shrivel up and get really curly, and the kind that stays really really flat, and the kind that just gets wrinkly on the edges. And each of those has five different classes underneath it." The next time you get a pork-related referand the business librarians attend group meetings and will be present for the final presentations.

"We're actually attaching ourselves to the group. We're taking more of an information consultant role, rather than doing a one-shot teaching session and saying, if you need us, here's where you can find us. At the same time, we're not giving them the answers. We still want to make it a teaching experience."

This is a new instructional approach for Bracke. "The head of our business library came to us from the University of Michigan business school, where they have a welldeveloped embedded librarian approach throughout the curriculum. She wanted to bring this to Purdue, and I thought this would be a great class to try this out. I took the idea to the business librarians and asked if ence question stumper, you'll know who to call!

\section{Agriculture is everything} plications that keep Bracke interested in agricultural sciences. "Agriculture effects the most basic parts of our lives. We need safe food, we need clean water, we need clothes. I think the global implications are really exciting. War-torn nations don't have things like clean water, or enough food, or safe food. These are all things that if we didn't have, our society would break down. Agriculture touches on everything."

If you enjoy working with down-to-earth people, looking for practical solutions to global problems, agricultural sciences librarianship may be the right field for you, too. $n$
At the end of the day, it's the broader im- 